\title{
Gene expression of matrix metalloproteinase 9 (MMP9), matrix metalloproteinase 13 (MMP13), vascular endothelial growth factor (VEGF) and fibroblast growth factor 23 (FGF23) in femur and vertebra tissues of the hypovitaminosis $D$ kyphotic pig model
}

\author{
Laura A. Amundson $^{1 *}$, Laura L. Hernandez ${ }^{2}$ and Thomas D. Crenshaw ${ }^{1}$ \\ ${ }^{1}$ Department of Animal Sciences, University of Wisconsin-Madison, Madison, WI 53706, USA \\ ${ }^{2}$ Department of Dairy Science, University of Wisconsin-Madison, Madison, WI 53706, USA \\ (Submitted 5 February 2018 - Accepted 24 May 2018 - First published online 11 July 2018)
}

\section{Abstract}

The hypovitaminosis D kyphotic pig provides a reliable model to study the initiation of bone lesions caused by maternal vitamin D (D) deficiencies. Matrix metalloproteinases (MMP; specifically, MMP9 and MMP13) and vascular endothelial growth factor (VEGF) are important in endochondral ossification and are potentially regulated by D. Fibroblast growth factor 23 (FGF23) is interrelated with D homoeostasis and bone mineralisation. Relative mRNA expression of MMP9, MMP13, VEGF and FGF23 was measured in pig femur and vertebra. Sows ( $n$ 37) were fed diets with $0(-\mathrm{D}), 8.125(+\mathrm{D})$ or $43.750(++\mathrm{D}) \mu \mathrm{g} \mathrm{D}_{3} / \mathrm{kg}$ throughout gestation and lactation. At weaning ( 3 weeks), pigs were fed diets with $0(-\mathrm{D})$ or $7.0(+\mathrm{D}) \mu \mathrm{g} \mathrm{D} / \mathrm{kg}$, each with 75 and $95 \%$ (LCaP) or 150 and $120 \%$ (HCaP) of the Ca and P requirements. Pigs at birth ( $n$ 27), 3 weeks $(n$ 27) and after the nursery period ( 7 weeks; $n$ 72) were euthanised for analysis. At 3 weeks, femur MMP9 expression of pigs produced by $+\mathrm{D}$ or $++\mathrm{D}$ sows was reduced $(P<0.05)$ to 0.5 -fold and $V E G F$ expression to 0.4 -fold compared with pigs from $-\mathrm{D}$ sows. At 7 weeks, $M M P 9$ expression was reduced $(P<0.05)$ to 0.45 -fold in femur and 0.58 -fold in vertebra from pigs produced by $+\mathrm{D}$ or $++\mathrm{D}$ sows compared with pigs from $-\mathrm{D}$ sows. Pig femur $V E G F$ expression was reduced to $0 \cdot 75$-fold in pigs produced by $++\mathrm{D}$ sows. $M M P 9$ and $V E G F$ mRNA expression offer potential markers for the initiation of bone lesions in the hypovitaminosis D kyphotic pig model.

\section{Key words: Maternal carryover: Matrix metalloproteinases: Vitamin D: Calcium: Phosphorus}

The hypovitaminosis D kyphotic pig model created and subsequently reproduced in our laboratory multiple times under controlled experimental conditions has provided a means to study the initiation of bone lesions and the role of maternal diet on factors involved in the offspring bone development ${ }^{(1)}$. Pigs produced by sows fed no or limited supplemental D during gestation and lactation are at risk of developing kyphosis if nutritionally challenged during their early growth phase ${ }^{(1,2)}$. The ability to reproduce the bone abnormality under controlled conditions offers an opportunity to study cellular signals involved in the initiation and early development of bone lesions, rather than characterise the final lesion as is commonly reported in most studies of animal and human bone abnormalities. A molecular understanding of the events and cell signals that lead to those final lesions will provide a means to monitor and potentially prevent the final lesion from ever occurring.
Hypovitaminosis D is typically associated with rachitic abnormalities in bone owing to the role of $\mathrm{D}$ in the regulation of mineral homoeostasis. In a previous experiment, pigs produced by sows fed limited D during gestation and lactation had a $25 \%$ reduction in whole-body bone mineral density as measured by dual-energy X-ray absorptiometry, but visible symptoms of kyphosis were not evident until the pigs were 8 weeks of age ${ }^{(3)}$. However, classical signs of rickets were not evident at any point. Recently, we have shown that the hypovitaminosis-Dinduced kyphosis cannot be predicted by common measures of $\mathrm{D}$ status such as serum $25-\mathrm{OH}-\mathrm{D}_{3}$ and body tissue stores of $\mathrm{D}^{(2)}$, even though these measurements are among the most common to evaluate D adequacy in both human and animal populations.

Additional bones, as well as the vertebrae, were affected in the hypovitaminosis D kyphotic pig model, even in pigs without visible presentation of spinal or limb deformities. Excised femurs from pigs produced by sows and fed dietary regiments during

Abbreviations: D, vitamin D; FGF23, fibroblast growth factor 23 ; Maternal diet: $-\mathrm{D}, 0 \mu \mathrm{g} \mathrm{D}_{3} / \mathrm{kg} ;+\mathrm{D}, 8 \cdot 125 \mu \mathrm{g} \mathrm{D}_{3} / \mathrm{kg} ;++\mathrm{D}, 43 \cdot 750 \mu \mathrm{g} \mathrm{D}_{3} / \mathrm{kg}$; where $1 \mathrm{IU}$ is defined as the biological activity of $0 \cdot 025 \mu \mathrm{g}$ cholecalciferol; MMP, matrix metalloproteinases; Nursery diet: $-\mathrm{D}, 0 \mu \mathrm{g} \mathrm{D}_{3} / \mathrm{kg} ;+\mathrm{D}, 7 \cdot 0 \mu \mathrm{g} \mathrm{D}_{3} / \mathrm{kg} ; \mathrm{LCa}$ and $\mathrm{HCa}$, 0.52 and $1.05 \%$; Nursery diet LP and HP, 0.57 and $0.72 \%$; VEGF, vascular endothelial growth factor; VDR, vitamin D receptor. 
growth known to induce kyphosis display gross abnormalities in the growth plate region and have reduced bone mineral content and mechanical properties ${ }^{(1,3)}$. The growth plate abnormalities are consistent with osteochondrosis-like lesions in which cartilage is retained and not replaced with mineralised bone. The resulting lesions reflect aberrant endochondral ossification, which results in dysregulated bone development.

Endochondral ossification, the manner by which long bones and vertebrae are formed, is a dynamic process that involves multiple cell types and localised cellular signals, which couple bone turnover and formation. During endochondral ossification, chondrocytes (cartilage cells), osteoblasts (bone forming cells), osteocytes (mature bone cells) and osteoclasts (bone resorbing cells) work in concert to form a cartilage matrix, which is subsequently calcified and replaced with mineralised bone. Endochondral ossification involves multiple steps with coordination of cell signals; however, the modelling and remodelling of the extracellular matrix is presumed to be the rate-limiting step ${ }^{(4,5)}$. Among the multiple proteins and cell signals involved in normal endochondral ossification, critical enzymes implicated in bone development and pathophysiology include the family of matrix metalloproteinases (MMP) and vascular endothelial growth factor $(\mathrm{VEGF})^{(4)}$.

The MMP are a group of $\mathrm{Zn}$-dependent enzymes responsible for degradation of matrix proteins during normal and aberrant growth. Initiation of enzyme function occurs during the early stages of embryonic development ${ }^{(6,7)}$, and certain MMP family members have been implicated in bone development. These proteins are closely regulated at the transcriptional level and are synthesised as zymogens, which undergo post-transcriptional and secretory regulation and require activation by each other or other proteinases ${ }^{(6,7)}$

Results from cell culture studies revealed evidence that MMP are needed to direct specific locations for the initiation and migration of osteoclasts ${ }^{(8)}$, an important event in extracellular matrix turnover. Two members of the MMP family, MMP9 and MMP13, provide critical roles for extracellular matrix turnover during bone modelling and remodelling. MMP9, a gelatinase, and MMP13, a collagenase, have been implicated in both normal and pathophysiological bone tissue development ${ }^{(4,9-11)}$

Animal knockout models of MMP9 and MMP13 have revealed severe bone phenotypes resulting from dysregulated growth plate development and ossification processes ${ }^{(12,13)}$. The MMP9 knockout model presented with a delay in endochondral ossification characterised by an enlarged hypertrophic cartilage zone, implying that MMP9 was involved in hypertrophic cartilage vascularisation and ossification ${ }^{(12)}$. In a separate model of MMP9 deficiency, the necessity for MMP9 to degrade the nonmineralised septae within the bone matrix was verified ${ }^{(14)}$.

The MMP13 knockout model displayed very similar bone phenotypes as observed in the MMP9 knockout model. The MMP $13^{-/-}$mouse displayed abnormally wide growth plates characterised by delayed chondrocyte turnover and ossification of the embryonic and adult skeleton ${ }^{(5,13)}$. The bone tissue abnormalities were attributed to decreased proteolysis of cartilage extracellular matrix and suppression of vascular invasion.

The $\mathrm{MMP}^{-/-} / \mathrm{MMP}^{-/-}$double knockout mouse had a more severe growth plate defect (expanded hypertrophic cartilage zone) than either single knockout ${ }^{(15)}$. In addition, if MMP9 was added to tissue culture with MMP13, the collagenolytic activity of MMP13 was twice as effective, implying a synergistic effect of MMP9 and MMP13 ${ }^{(14)}$. Studies in which VEGF was inhibited have revealed similar growth plate phenotypes as MMP9 and MMP13 knockout models. Inhibition of VEGF leads to impaired bone formation, an expanded hypertrophic cartilage zone and almost complete suppression of blood vessel invasion of the growth plate $e^{(16,17)}$

The MMP have high specificity for their respective substrates and therefore work in concert to degrade the milieu of proteins present in the extracellular matrix. The cooperative work of MMP proteins during turnover of the extracellular matrix allows for the release of additional extracellular matrix proteins, which further direct localised endochondral ossification processes. An example is VEGF, which remains inactive until released by the combined actions of MMP9 and MMP13 ${ }^{(14)}$.

The angiogenic factor, VEGF, is expressed by endothelial cells and hypertrophic chondrocytes ${ }^{(16-18)}$. Angiogenesis is necessary for proper endochondral bone formation as cartilage is an avascular tissue, which is replaced by ossified bone, a highly vascular tissue $^{(16)}$. As reviewed by Carlevaro et al. ${ }^{(16)}$. and Murata et al. ${ }^{(17)}$, VEGF is essential for physiological angiogenesis, growth plate development and endochondral ossification.

Previous research has shown that MMP9, MMP13 and VEGF can be regulated by $\mathrm{D}$. In mice treated with the active metabolite, $1 \alpha, 25(\mathrm{OH})_{2} \mathrm{D}_{3}, M M P 9$ mRNA and MMP9 protein expressions were increased ${ }^{(19)}$. In cell culture, $1 \alpha, 25(\mathrm{OH})_{2} \mathrm{D}_{3}$ indirectly induced an increase in MMP13 mRNA expression by mouse osteoblast-like cells ${ }^{(20)}$. In addition, vitamin D increased transcription of $V E G F^{(19)}$. However, the in vivo effects of dietary D on these factors in intact tissues has not been reported.

Therefore, given the in vitro evidence for the roles of MMP9, MMP13 and VEGF in extracellular matrix turnover, the ratelimiting step of endochondral ossification and their potential relationship with vitamin $\mathrm{D}$, these factors are excellent candidates to measure in the hypovitaminosis D kyphotic pig model to assess their potential role in bone lesion initiation and development.

As mentioned earlier, the hypovitaminosis D kyphotic pig model also revealed a carryover effect of maternal dietary D on whole-body bone mineralisation that persisted well into the growth cycle of the offspring. A more recently discovered phosphaturic hormone, fibroblast growth factor 23 (FGF23), has been implicated in pathophysiological bone phenotypes associated with diseases such as hypophosphatemic rickets and chronic kidney disease. Mouse knockout and disease models are consistent with a role of FGF23 in bone mineralisation. However, the indirect actions of FGF23 on bone through mineral homoeostasis $v$. the direct actions of FGF23 on bone mineralisation factors is still not completely understood. FGF23 is primarily produced in osteoblast and osteocyte cells and is responsible for $\mathrm{P}$ homoeostasis through a pathway that involves feedback regulation between FGF23, D, $\mathrm{P}^{(21,22)}$ and $\mathrm{Ca}^{(23,24)}$. Increased FGF23 acts on the kidney to decrease the $\mathrm{D}$ anabolic enzyme, $1 \alpha$-hydroxylase, and the sodium phosphate transporters to elicit an overall decrease in serum active $\mathrm{D}$ and $\mathrm{P}^{(21,22)}$. The role of FGF23 in response to dietary vitamin D inputs in a physiologically unaltered animal model remains to 
be explored and understood. Therefore, given the abnormal bone mineralisation of pigs subject to conditions known to induce kyphosis, FGF23 is another candidate for a potentially dysregulated cellular signal associated with the initiation and development of bone lesions in the hypovitaminosis D kyphotic pig model.

The objective of results reported herein was to determine the relative mRNA expression of FGF23, MMP9, MMP13 and VEGF in the femur and vertebra of pigs produced by sows and fed nursery diets known to induce kyphosis. Results reported are from pigs that were part of a larger study that examined the accuracy of serum vitamin D analysis to predict bone abnormalities ${ }^{(2)}$ and the prolonged effects of maternal dietary $\mathrm{D}$ deficiency on spinal curvature as a model for human kyphosis ${ }^{(25)}$. However, the purpose of the current results was to study expression of selected molecular signals in tissues from these pigs before they developed gross outward signs of kyphosis. The selection of an early age was intended to identify changes in cellular signals that may be pivotal in the initiation of bone lesions and therefore provide potential targets for maternal dietary D during offspring bone development. The hypovitaminosis D kyphotic pig model provides a physiologically relevant, genetically and physically unaltered model to understand maternal dietary effects on long-term bone development. These results will aid in both animal and human bone development research and understanding.

\section{Methods}

\section{Ethics statement}

All animal procedures were approved (Protocol A00865) by the College of Agricultural and Life Sciences Animal Care and Use
Committee, University of Wisconsin-Madison. Animals selected for tissue collections were humanely euthanised by electrical stunning followed by exsanguination.

\section{Experimental design and diets}

The complete experimental design (Fig. 1) and dietary compositions used in the study were described by Amundson et $a l{ }^{(2)}$. Briefly, crossbred (PIC Large White $\times$ Landrace) first parity sows ( $n$ 37) were bred via artificial insemination with semen collected from an individual Line 19 boar (PIC Inc.). At breeding, sows were randomly assigned ( $n$ 12, 12 and 13/ treatment, respectively) to one of three dietary treatments that varied in D supplementation to provide $0(-\mathrm{D}), 8 \cdot 125(+\mathrm{D})$ or 43.750 (++D) $\mu \mathrm{g}$ vitamin $\mathrm{D}_{3} / \mathrm{kg}$ diet. Sows were fed their respective dietary treatments throughout gestation and lactation phases and were allowed to complete parturition naturally. Pigs were weaned after a 24.7 (SEM 0.6)-d lactation period (3 weeks) and randomly assigned within sow treatment to one of four nursery dietary treatments that varied in vitamin $\mathrm{D}, \mathrm{Ca}$ and $\mathrm{P}$ concentrations to comprise the twelve dietary treatment groups for the pigs during the nursery phase. The four nursery dietary treatments were arranged in a $2 \times 2$ factorial design with nursery diets formulated to supply either $0 \quad(-\mathrm{D})$ or $7 \cdot 0 \quad(+\mathrm{D}) \mu \mathrm{g}$ vitamin $\mathrm{D}_{3} / \mathrm{kg}$, each with 75 and $95 \%$ (LCaP) or 150 and $120 \%$ (HCaP) of the $\mathrm{Ca}$ and $\mathrm{P}$ requirements for $10-20 \mathrm{~kg}$ pigs $^{(26)}$, respectively. At weaning, pigs were fed an adjustment diet with no supplemental D for 1 week, before being fed treatment diets for 3 weeks for a total nursery phase duration of 4 weeks. The 1-week adjustment diet included whey protein and was fed to allow pigs to transition from weaning to solid feed. The nursery phase concluded at $52 \cdot 4$ (SEM $0 \cdot 17$ ) d of age ( 7 weeks).

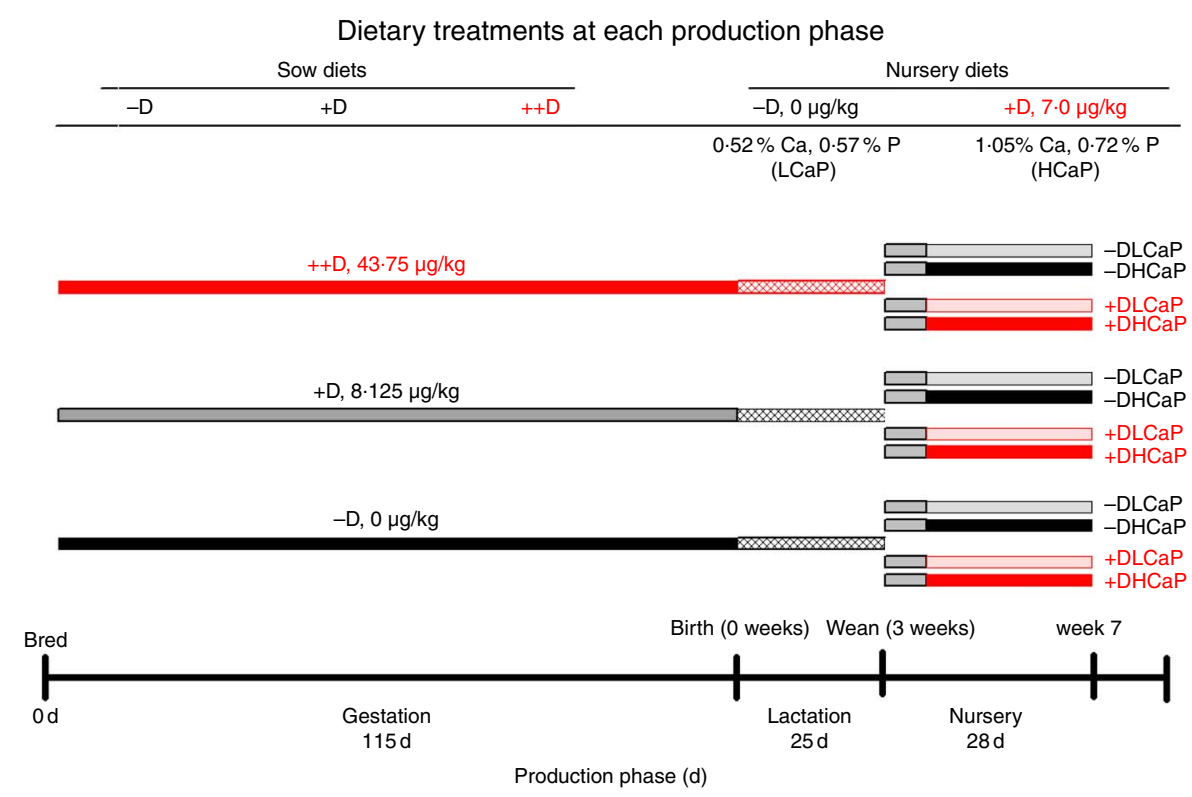

Fig. 1. Timeline of dietary treatments fed to sows during gestation and lactation and diets fed to nursery pigs. Maternal diets were formulated to supply 0 ( $-D)$, $8 \cdot 125$ $(+D)$ or $43.750(++D) \mu \mathrm{g}$ vitamin $D_{3} / \mathrm{kg}$ diet in complete diets fed from breeding through the lactation phase. Nursery diets were formulated to supply either $0 \mu \mathrm{g}$ vitamin $\mathrm{D}_{3} / \mathrm{kg}(-\mathrm{D})$ or $7.0 \mu \mathrm{g}$ vitamin $\mathrm{D}_{3} / \mathrm{kg}(+\mathrm{D})$ and either 75 and $95 \%(\mathrm{LCaP})$ or 150 and $120 \%(\mathrm{HCaP})$ of the Ca and P requirements, respectively, for $10--20-\mathrm{kg}$ pigs. Pigs were fed an adjustment diet during the 1st week of the nursery, which was consistent with routine diets fed to the herd (whey, maize, soyabean meal and oat groats), except the diet contained no supplemental vitamin D. 
Tissue samples were collected from pigs at 0 ( $n$ 27), 3 ( $n$ 27) and 7 ( $n$ 72) weeks for molecular analysis, before the age at which the outward spinal curvature due to kyphosis is visible based on our earlier results ${ }^{(1,2)}$ The earlier age for tissue collection was selected, as our objective was to evaluate the initiation and early developmental stages of the bone lesions.

\section{Quantitative real-time PCR}

Bone sections of the distal femur and 15th vertebral body (vertebra) were collected immediately after euthanasia of each pig, snap-frozen in liquid $\mathrm{N}_{2}$ and stored at $-80^{\circ} \mathrm{C}$ until quantitative real-time PCR (qPCR) analysis. Longitudinal slabs (approximately $1 \mathrm{~mm}$ ) of the distal femur, including both the epiphysis and metaphysis regions immediately surrounding and including the growth plate region, were collected. A midsection, longitudinal slab to the entire vertebral body was collected. The RNA isolation and qPCR analyses were completed as described previously ${ }^{(2)}$. Relative femur and vertebra mRNA expression levels of $M M P 9, M M P 13, V E G F$ and FGF23 were measured and normalised to vitamin $D$ receptor (VDR), which was verified to be stably expressed across treatments within each tissue. Considerable effort was devoted to identify and select VDR as a housekeeping gene for use as a control. Critical criteria for selection of a suitable housekeeping gene is that its expression does not change across treatment groups in the tissues being compared. Given that there were twelve treatment groups at the end of the nursery phase, the identification of a qualified housekeeping gene was quite a challenge. Commonly used genes such as GAPDH or actin did not qualify, as the expression was not stable across treatments (data not shown). Although not a 'classical' housekeeping gene, VDR was the most stably expressed gene with the tightest range of $\mathrm{Ct}$ values across the 12 nursery treatments study even though diets were supplemented with variable concentrations of $\mathrm{D}, \mathrm{Ca}$ and $\mathrm{P}$. The qPCR data were analysed using the $2^{-\Delta \Delta C_{T}} \operatorname{method}^{(27)}$ with pigs produced by sows fed $-\mathrm{D}$ diets serving as the control for samples at birth (0 week) and 3 weeks and pigs produced by sows fed -D diets and fed-DLCaP nursery diets serving as the control for samples at 7 weeks. Primer sequences are listed in Table 1. Primer sequences were designed with the Primer3 program based on gene sequences obtained from the National Center for Biotechnology Information, except for $V D R^{(28)}$

\section{Statistical analysis}

Data were analysed by regression analysis using mixed models, general linear models and rank (if data were not normally distributed) procedures using SAS version 9.3 (SAS Institute Inc.) as described previously ${ }^{(2)}$. Briefly, analysis of data collected from pigs at 0 and 3 weeks involved a randomised block design. Analysis of data from samples collected from pigs at 7 weeks involved a $3 \times 4$ factorial arrangement of treatments analysed as a split-plot design. Maternal diets $(-D,+D,++D)$ were the main plot fixed effect units. The split-plot units were nursery treatment groups (-DLCaP, -DHCaP, +DLCaP, $+\mathrm{DHCaP}$, arranged as a $2 \times 2$ factorial), and the two-way interaction with maternal diets and nursery diets. Even though maternal diets were fed to sows, the sow responses to diets were not evaluated in this experiment. The individual pig was considered the experimental unit, as only one pig from each litter was sampled at the age periods. Differences owing to pig sex were not considered in the analysis. Inferences among treatment groups were based on orthogonal contrasts used to identify the main effects attributed to variation among maternal diets $(-\mathrm{D} v,+\mathrm{D},++\mathrm{D}$ and $+\mathrm{D} v,++\mathrm{D})$, effects due to nursery diets (D effect $(-\mathrm{D} v++\mathrm{D}), \mathrm{CaP}$ effect (LCaP $v$. HCaP) and the $\mathrm{D} \times \mathrm{CaP}$ interaction) and effects due to the interaction between maternal and nursery diets. Significance was considered at $P \leq 0.05$ and trends at $P \leq 0 \cdot 10$. Results are reported as the average values for each trait within three ( 0 and 3 weeks) or twelve ( 7 weeks) dietary treatments groups with a pooled standard error of the mean. The standard error of the mean was calculated by dividing the root mean square of the random error term in the regression model by the square root of the average number of observations within treatment groups. For the mRNA expression data, a power analysis for a hypothesised effect size of 2 , an $\alpha$ of 0.05 and power set at $80 \%$, the required sample size was five per treatment. However, given the fallacies associated with power calculations ${ }^{(29)}$, the calculation may be misleading and therefore of unknown merit.

\section{Results \\ MMP9 expression}

In pigs at birth ( 0 weeks), no differences were detected in femur (Fig. 2(a)) or vertebra (Fig. 3(a)) relative MMP9 expression among maternal dietary D treatment groups. Differences were

Table 1. Primer sequences for housekeeping gene and genes of interest for quantification by real-time quantitative real-time PCR (qPCR) ${ }^{\star}$

\begin{tabular}{lll}
\hline Primers & Forward $\left(5^{\prime}-3^{\prime}\right)$ & Reverse $\left(5^{\prime}-3^{\prime}\right)$ \\
\hline $\begin{array}{l}\text { Housekeeping } \\
\text { VDR }\end{array}$ & TTGCCAAACACCTCAAGCACAAGG & \\
$\begin{array}{l}\text { Genes of Interest } \\
M M P 9\end{array}$ & TGCTCTACGCCAAGATGATCCAGA \\
MMP13 & ACCGGCTCTAAAGCTTCTCC & TCAAAGGTCTGGAATTTGCC \\
VEGF & CTGCACTAGGTACCACTGGG & AAAGCATGAGCCAACAGACC \\
FGF23 & CTTTCTGCTCTCTTGGGTGC & GAACTTCACCACTTCGTGGG \\
\hline
\end{tabular}

$V D R$, vitamin D receptor; $M M P 9$, matrix metalloproteinase 9; MMP13, matrix metalloproteinase 13; VEGF, vascular endothelial growth factor; FGF 23, fibroblast growth factor 23.

* Forward and reverse sequences for primers used to analyse mRNA content using qPCR. 
(a)

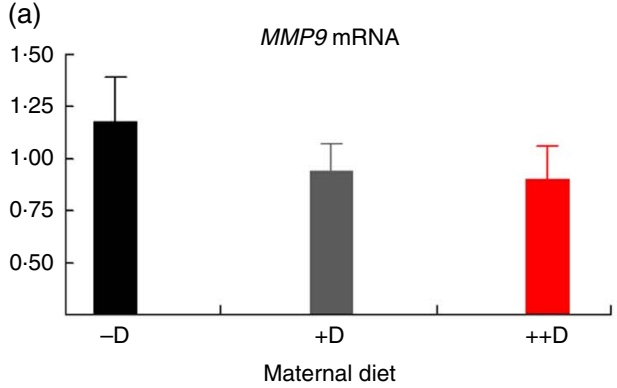

(c)

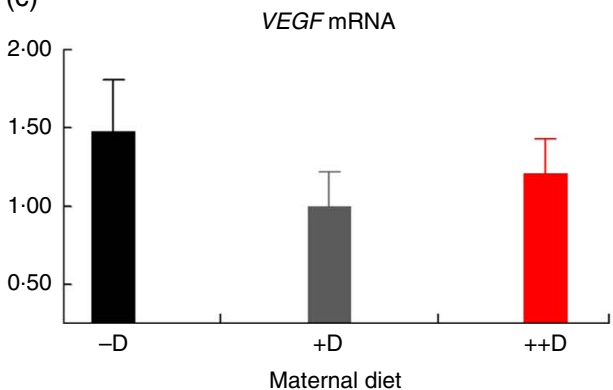

(b)

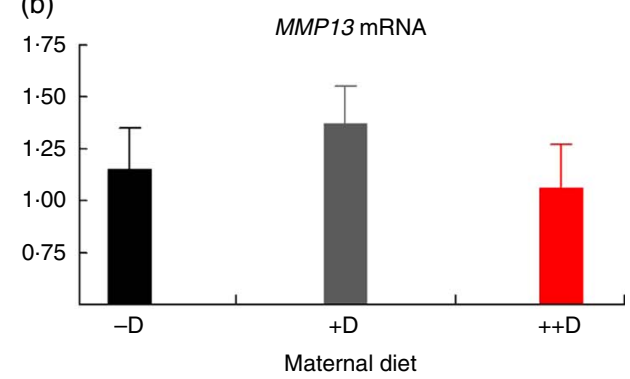

(d)

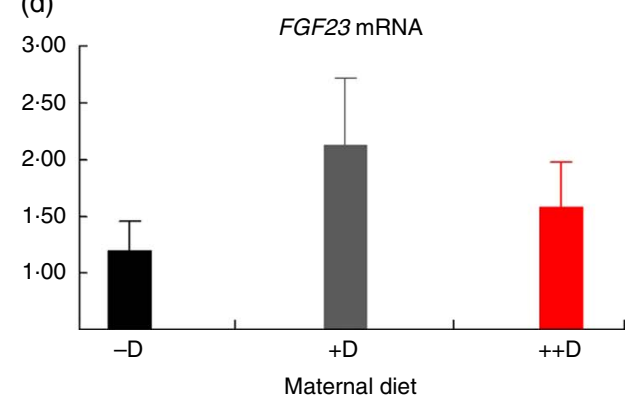

Fig. 2. Femur relative mRNA expression of matrix metalloproteinase 9 (MMP9) (a), matrix metalloproteinase 13 (MMP13) (b), vascular endothelial growth factor (VEGF) (c) or fibroblast growth factor 23 (FGF23) (d) from pigs at birth (0 weeks) across maternal dietary treatments. Values are means ( $n 8$ to 9 tissues per treatment), with their standard errors of the relative fold change compared with the control $(-D)$, normalised to vitamin $D$ receptor. $-D, 0 \mu \mathrm{g}$ vitamin $D_{3} / \mathrm{kg}$ diet; $+D, 8 \cdot 125 \mu \mathrm{g}$ vitamin $\mathrm{D}_{3} / \mathrm{kg}$ diet; ++D, $43.750 \mu \mathrm{g}$ vitamin $\mathrm{D}_{3} / \mathrm{kg}$ diet.

(a)

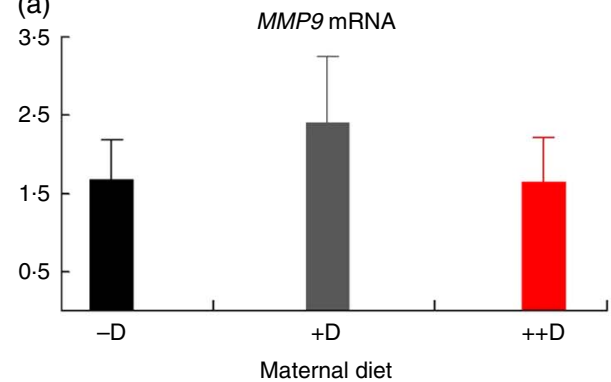

(c)

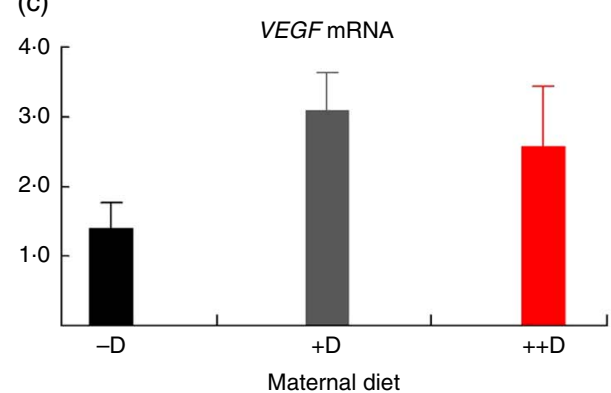

(b)

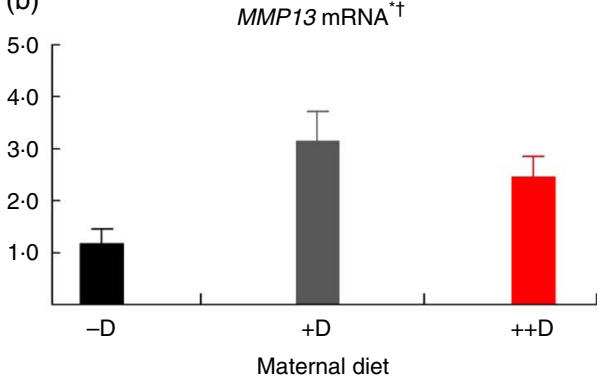

(d)

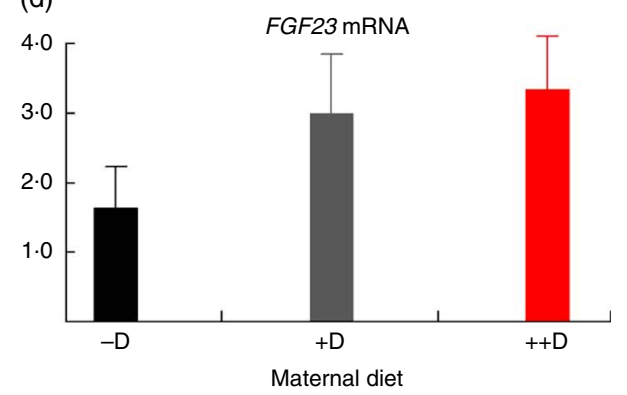

Fig. 3. Vertebra relative mRNA expression of matrix metalloproteinase 9 (MMP9) (a), matrix metalloproteinase 13 (MMP13) (b), vascular endothelial growth factor (VEGF) (c) or fibroblast growth factor 23 (FGF23) (d) from pigs at birth ( 0 weeks) across maternal dietary treatments. Values are means ( 4 to 9 tissues per treatment), with their standard errors of the relative fold change compared with the control (-D), normalised to vitamin $D$ receptor. ${ }^{*}$ Difference due to maternal diet, $P \leq 0.05$; $\dagger$ maternal diet $-\mathrm{D} v .+\mathrm{D}$ and $++\mathrm{D}$ differ, $P \leq 0.05 .-\mathrm{D}, 0 \mu \mathrm{g}$ vitamin $\mathrm{D}_{3} / \mathrm{kg}$ diet; $+\mathrm{D}, 8.125 \mu \mathrm{g}$ vitamin $\mathrm{D}_{3} / \mathrm{kg}$ diet; $++\mathrm{D}, 43.750 \mu \mathrm{g}$ vitamin $\mathrm{D}_{3} / \mathrm{kg}$ diet.

detected in relative $M M P 9$ expression at 3 weeks but only in femur tissue. Pigs produced by $+\mathrm{D}$ or $++\mathrm{D}$ sows had reduced femur $M M P 9$ expression that was approximately $0 \cdot 5$-fold of that in pigs produced by $-\mathrm{D}$ sows. Therefore, transcriptional differences due to maternal dietary $\mathrm{D}$ were evident as early as
3 weeks. Opposite trends were observed in $M M P 9$ expression in vertebra, but differences among maternal diets were not significant. The lack of significance can be largely attributed to the large variation in the vertebra tissue (Fig. 5(a)) compared with the femur (Fig. 4(a)), most likely caused by the relatively small 
(a)

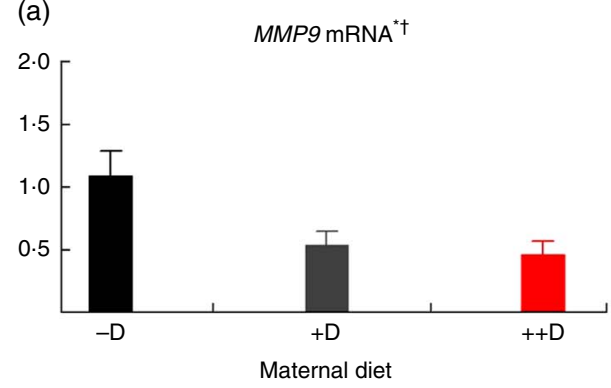

(c)

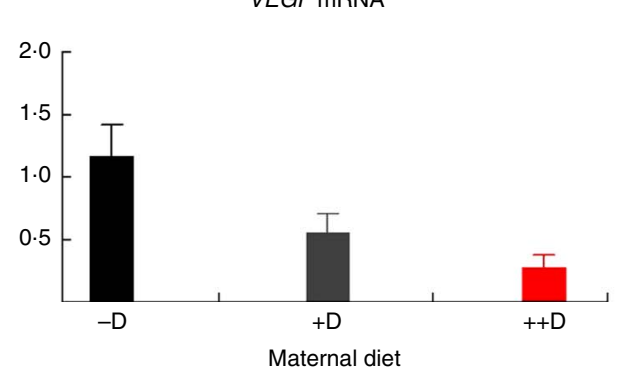

(b)

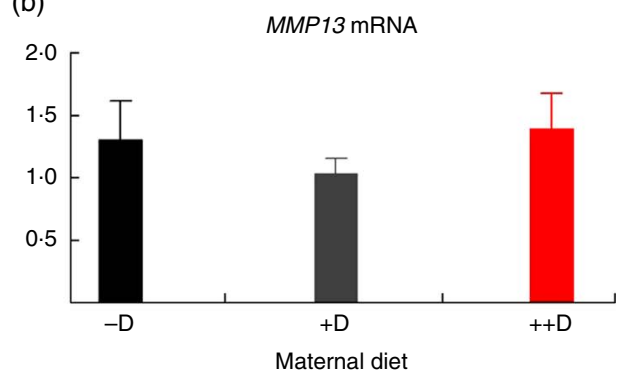

(d)

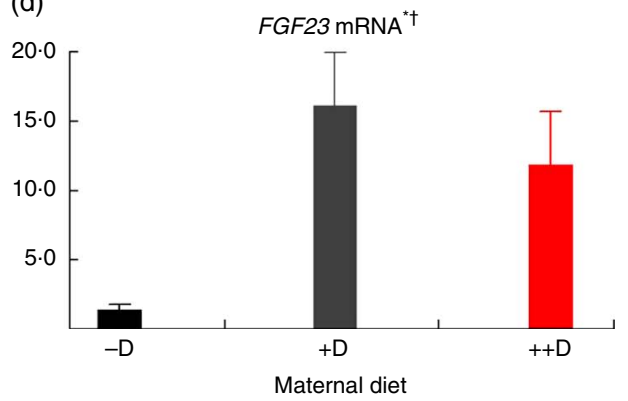

Fig 4. Femur relative mRNA expression of matrix metalloproteinase $9(M M P 9)(a)$, matrix metalloproteinase 13 (MMP13) (b), vascular endothelial growth factor (VEGF) (c) or fibroblast growth factor 23 (FGF23) (d) from pigs at weaning (3 weeks) across maternal dietary treatments. Values are means ( $n 6$ to 9 tissues per treatment), with their standard errors of the relative fold change compared with the control (-D), normalised to vitamin $D$ receptor. * Difference due to maternal diet, $P \leq 0.05$; † maternal diet $-\mathrm{D} v$. $+\mathrm{D}$ and $++\mathrm{D}$ differ, $P \leq 0.05$; † maternal diet $+\mathrm{D} v$. ++D differ, $P \leq 0.10 .-\mathrm{D}, 0 \mu \mathrm{g}$ vitamin $\mathrm{D}_{3} / \mathrm{kg}$ diet; $+\mathrm{D}, 8 \cdot 125 \mu \mathrm{g}$ vitamin $\mathrm{D}_{3} / \mathrm{kg}$ diet; $++\mathrm{D}$, $43.750 \mu \mathrm{g}$ vitamin $\mathrm{D}_{3} / \mathrm{kg}$ diet.

(a)

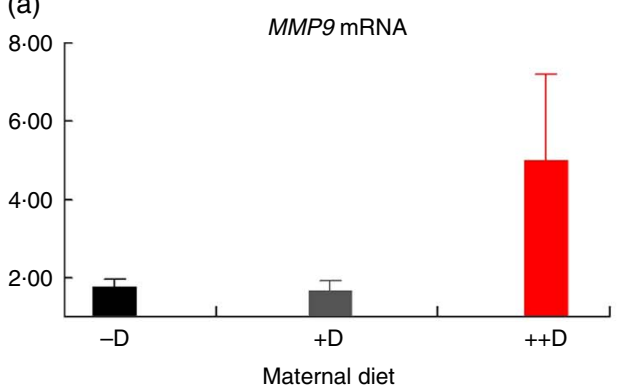

(c)

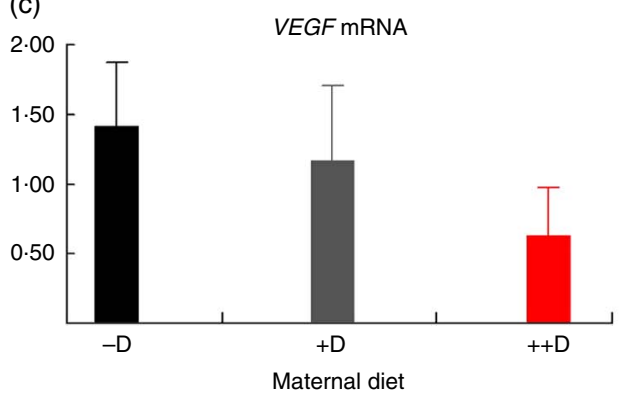

(b)

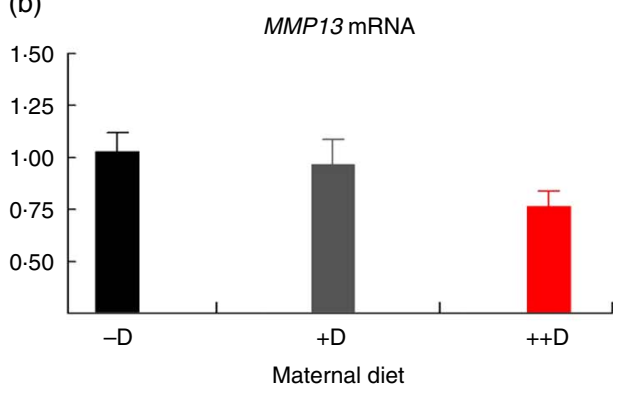

(d)

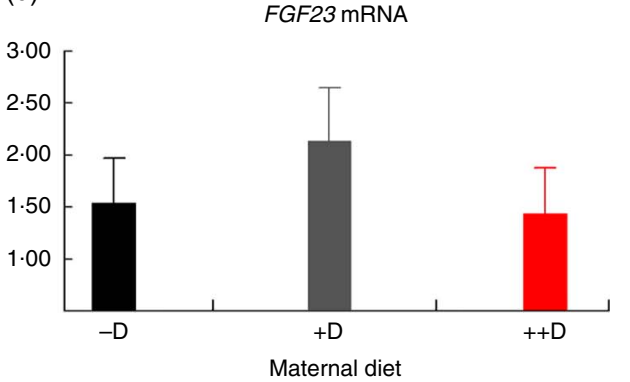

Fig. 5. Vertebra relative mRNA expression of matrix metalloproteinase $9(M M P 9)(a)$, matrix metalloproteinase $13(M M P 13)(b)$, vascular endothelial growth factor (VEGF) (c) or fibroblast growth factor 23 (FGF23) (d) from pigs at weaning (3 weeks) across maternal dietary treatments. Values are means $(n 5$ to 9 tissues per treatment), with their standard errors of the relative fold change compared with the control (-D), normalised to vitamin $D$ receptor. $-D, 0 \mu g$ vitamin $D_{3} / k g$ diet; $+D$, $8.125 \mu \mathrm{g}$ vitamin $D_{3} / \mathrm{kg}$ diet; $++\mathrm{D}, 43.750 \mu \mathrm{g}$ vitamin $D_{3} / \mathrm{kg}$ diet.

amount of tissue from pigs at this age, and therefore needs to be replicated in future experiments. Although this experiment was not designed to decipher between gestation and lactation effects, the lack of a detectable difference at 0 weeks does not preclude a gestation diet effect. As described in our previous experiment, maternal dietary $\mathrm{D}$ failed to alter milk $25-\mathrm{OH}-\mathrm{D}_{3}$ levels in this 
(a)

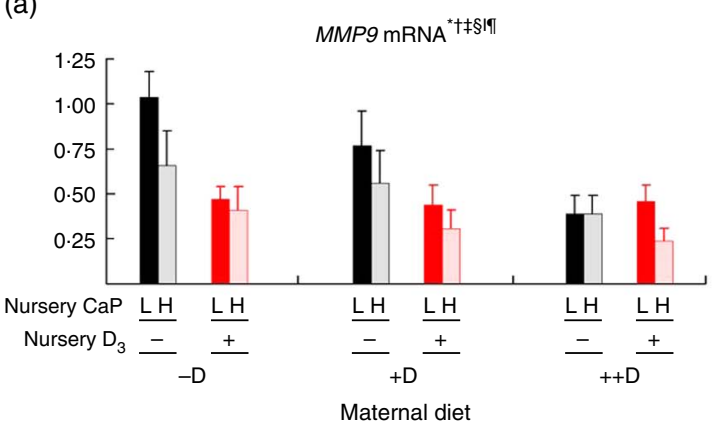

(c)

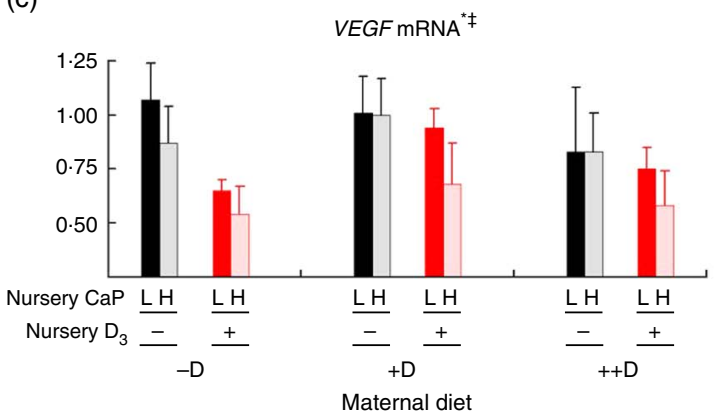

(b)

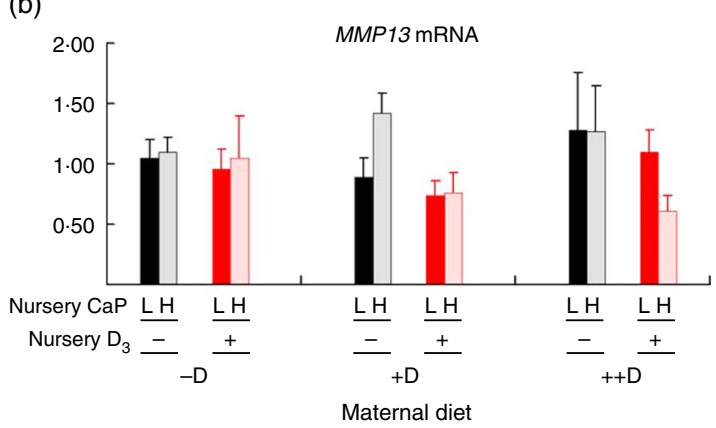

(d)

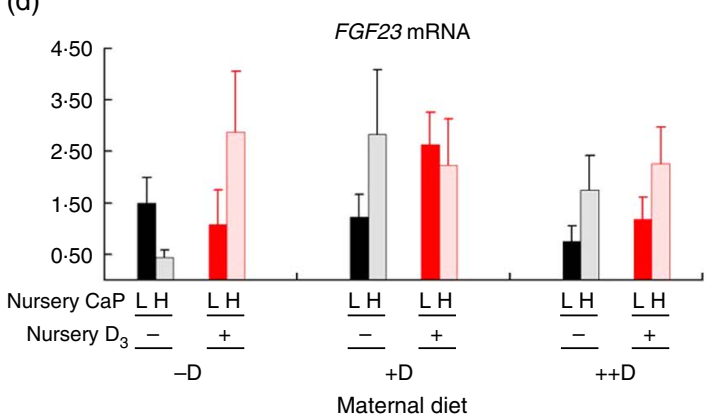

Fig. 6. Femur relative mRNA expression of matrix metalloproteinase 9 (MMP9) (a), matrix metalloproteinase 13 (MMP13) (b), vascular endothelial growth factor $($ VEGF) (c) or fibroblast growth factor 23 (FGF23) (d) from pigs at the end of nursery (7 weeks) across maternal and nursery dietary treatments. Values are means $(n 4$ to 6 tissues per treatment), with their standard errors of the relative fold change compared with the control ( $-\mathrm{D}$ maternal diet and $-\mathrm{DL}$ nursery diet), normalised to vitamin D receptor. * Difference due to maternal diet, $P \leq 0.05 ; \dagger$ maternal diet $-\mathrm{D} v$. $+\mathrm{D}$ and $++\mathrm{D}$ differ, $P \leq 0.05 ; \ddagger$ maternal diet $+\mathrm{D} v$. $++\mathrm{D}$ differ, $P \leq 0.05 ; \S$ difference due to nursery diet, $P \leq 0.10 ; \|$ nursery diet CaP effect, $P \leq 0.10 ; \uparrow$ nursery diet $\mathrm{D}$ effect, $P \leq 0.05$. Maternal diets: $-\mathrm{D}, 0 \mu \mathrm{g}$ vitamin $\mathrm{D}_{3} / \mathrm{kg}$ diet; $+\mathrm{D}, 8.125 \mu \mathrm{g}$ vitamin $\mathrm{D}_{3} / \mathrm{kg}$ diet; ++D, $43.750 \mu \mathrm{g}$ vitamin $D_{3} / \mathrm{kg}$ diet. Nursery diets: $-\mathrm{D}, 0 \mu \mathrm{g}$ vitamin $\mathrm{D}_{3} / \mathrm{kg}$ diet; $+\mathrm{D}, 7.0 \mu \mathrm{g}$ vitamin $\mathrm{D}_{3} / \mathrm{kg}$ diet; $\mathrm{L}, 75$ and $95 \%$ of the $C$ a and $P$ requirements, respectively, $\mathrm{H}, 150$ and $120 \%$ of the $\mathrm{Ca}$ and $\mathrm{P}$ requirements, respectively.

experiment, and therefore an affect due to the $\mathrm{D}$ status of the milk would not be expected to attribute to differences detected at weaning $(3 \text { weeks })^{(2)}$. Further experiments need to be conducted to decipher between gestation and lactation effects.

Most notably, maternal dietary D continued to influence both pig femur (Fig. 6(a)) and vertebra (Fig. 7(a)) relative MMP9 expression at 7 weeks of age, regardless of the nursery dietary treatment the pig consumed. Pooled across nursery dietary treatments, expression was reduced $(P \leq 0.05)$ to 0.52 -fold and $0 \cdot 37$-fold in femurs from pigs produced by $+\mathrm{D}$ or $++\mathrm{D}$ sows, respectively, compared with cohorts produced by $-\mathrm{D}$ sows (0.64-fold). In vertebra, MMP9 expression was reduced $(P \leq 0.05)$ to 0.58 -fold in vertebra from pigs produced by $+\mathrm{D}$ and $++\mathrm{D}$ sows compared with cohorts produced by $-\mathrm{D}$ sows (0.95-fold). These results imply that maternal dietary D levels during gestation and lactation had prolonged effects on pig $M M P 9$ transcription regardless of dietary $\mathrm{D}$ concentrations during the 4-week nursery phase. In addition, dietary D supplementation in the nursery diets decreased MMP9 mRNA expression in femur tissue, but differences were not detected in vertebra tissue. Pooled across maternal dietary treatments, expression was reduced $(P \leq 0.05)$ to 0.38 -fold in pigs fed $+\mathrm{D}$ nursery diets compared with cohorts fed $-\mathrm{D}$ nursery diets $(0.63$ fold). Therefore, maternal nursery dietary D affected MMP9 expression in the same manner but as separate affects, as an interaction between maternal and nursery diets was not detected. The discrepancy between femur and vertebra tissue response to nursery dietary $\mathrm{D}$ is not completely understood.

\section{MMP13 expression}

No differences in femur relative $M M P 13$ expression were detected in pigs at any age (Fig. 2(b), 4(b) and 6(b)). However, differences were detected in vertebra relative MMP13 mRNA expression. At 0 weeks, MMP13 mRNA expression was increased $(P \leq 0.05)$ approximately 2 -fold in pigs produced by $+\mathrm{D}$ and $++\mathrm{D}$ sows compared with cohorts produced by $-\mathrm{D}$ sows (Fig. 3(b)), but no differences were detected in vertebra MMP13 mRNA expression at 3 weeks (Fig. 5(b)).

As mentioned for MMP9 expression, maternal dietary D continued to influence pig MMP13 expression at the end of the nursery phase. Pooled across nursery dietary treatments, pigs produced by $+\mathrm{D}$ and $++\mathrm{D}$ sows tended to have reduced $(P \leq 0 \cdot 10)$ vertebrae $M M P 13$ expression to approximately $0 \cdot 74-$ fold compared with cohorts produced by $-\mathrm{D}$ sows (0.97-fold; Fig. 7(b)). The discrepancies between MMP13 vertebra expression at 3 and 7 weeks and between vertebra and femur tissue is not completely understood. Potentially the vertebra tissue undergoes modelling and remodelling at a greater rate than the femur at these ages; therefore, the vertebra would require increased amounts of enzyme expression for matrix turnover.

\section{VEGF expression}

No differences in vertebra relative $V E G F$ expression were detected in pigs at any age (Fig. 3(c), 5(c) and 7(c)). Differences 
(a)

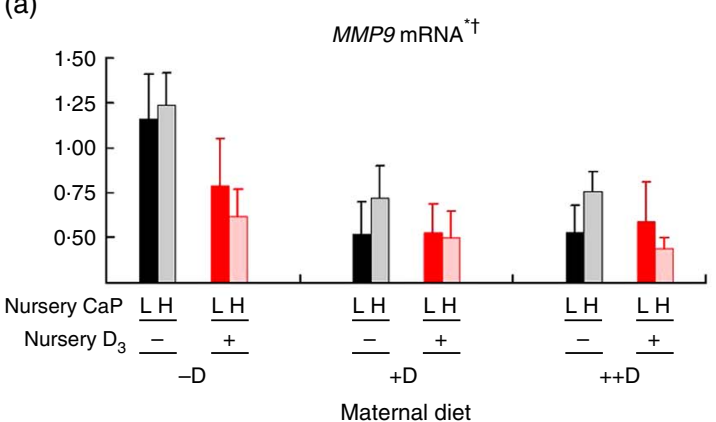

(c)

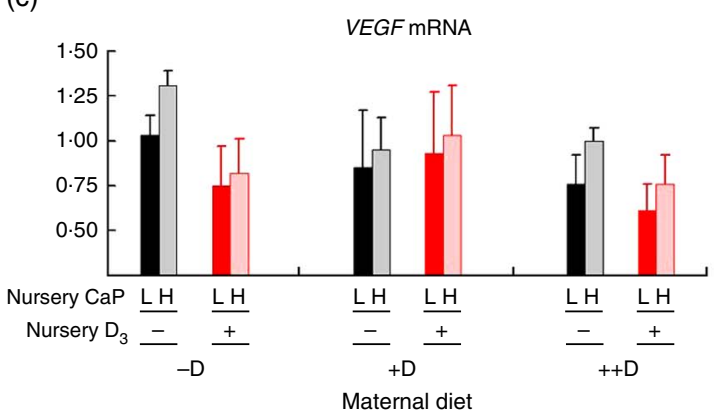

(b)

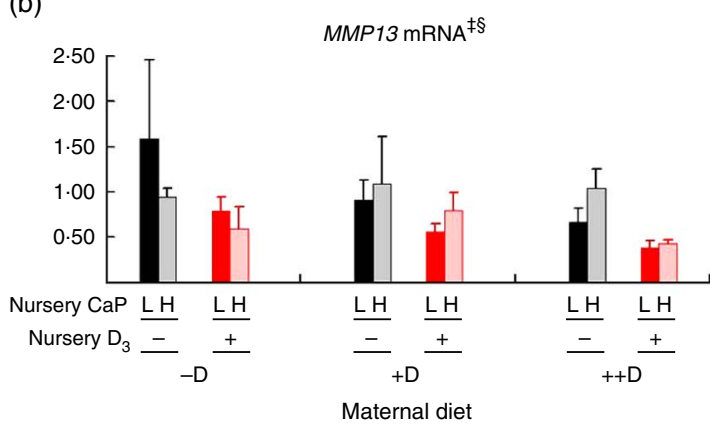

(d)

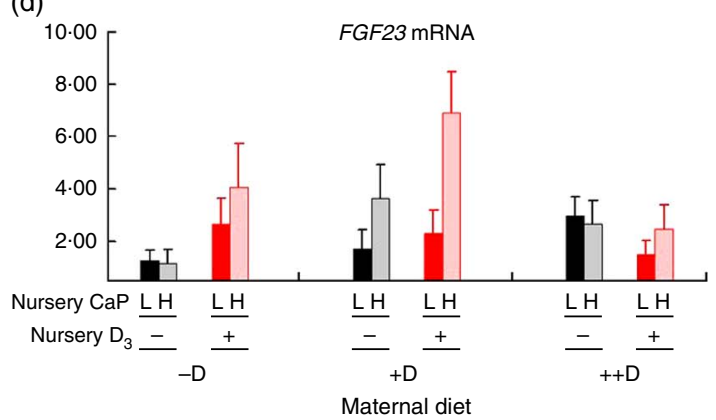

Fig. 7. Vertebra relative mRNA expression of matrix metalloproteinase 9 (MMP9) (a), matrix metalloproteinase 13 (MMP13) (b), vascular endothelial growth factor (VEGF) (c) or fibroblast growth factor 23 (FGF23) (d) from pigs at the end of nursery (7 weeks) across maternal and nursery dietary treatments. Values are means ( $n 4$ to 6 tissues per treatment), with their standard errors of the relative fold change compared with the control (-D maternal diet and -DL nursery diet), normalised to vitamin $\mathrm{D}$ receptor $(V D R)$. ${ }^{*}$ Difference due to maternal diet, $P \leq 0.05 ; \dagger$ maternal diet $-\mathrm{D} v .+\mathrm{D}$ and $++\mathrm{D}$ differ, $P \leq 0.05 ; \ddagger$ difference due to maternal diet, $P \leq 0.10 ; \S$ maternal diet $-\mathrm{D} v$. $+\mathrm{D}$ and $++\mathrm{D}$ differ, $P \leq 0 \cdot 10$. Maternal diets: $-\mathrm{D}, 0 \mu \mathrm{g}$ vitamin $\mathrm{D}_{3} / \mathrm{kg}$ diet; $+\mathrm{D}, 8.125 \mu \mathrm{g}$ vitamin $\mathrm{D}_{3} / \mathrm{kg}$ diet; ++D, $43.750 \mu \mathrm{g}$ vitamin $\mathrm{D}_{3} / \mathrm{kg}$ diet. Nursery diets: $-D, 0 \mu g$ vitamin $D_{3} / \mathrm{kg}$ diet; $+\mathrm{D}, 7.0 \mu \mathrm{g}$ vitamin $\mathrm{D}_{3} / \mathrm{kg}$ diet; L, 75 and $95 \%$ of the Ca and P requirements, respectively, $\mathrm{H}, 150$ and $120 \%$ of the Ca and P requirements, respectively.

were detected in femur relative $V E G F$ expression in pigs at 3 and 7 weeks but not at 0 weeks (Fig. 2(c), 4(c) and 6(c)). At 3 weeks, femur $V E G F$ expression was reduced to approximately 0.5 -fold $(P \leq 0.05)$ or 0.3 -fold $(P \leq 0.05)$ in pigs produced by $+\mathrm{D}$ or $++\mathrm{D}$ sows, respectively, compared with pigs produced by -D sows (1.17-fold; Fig. 4(c)). Relative VEGF expression was reduced proportionately to $M M P 9$ expression in femur tissue, which may not be surprising given the relationship between MMP9 and VEGF mentioned earlier.

Interestingly at 7 weeks, differences in femur VEGF expression were due only to maternal dietary treatment, not nursery diet (Fig. 6(c)). Pooled across nursery dietary treatments, pig femur relative $V E G F$ expression was reduced $(P \leq 0.05)$ to 0.75 fold in pigs produced by $++\mathrm{D}$ sows compared with cohorts produced by $-\mathrm{D}$ and $+\mathrm{D}$ sows (0.84-fold). As with $M M P 9$ mRNA expression, these results indicate a prolonged effect of maternal dietary D on pig mRNA expression at the end of the 4-week nursery phase.

\section{FGF23 expression}

The only differences detected in relative FGF23 mRNA expression were in femur tissue of pigs at 3 weeks (Fig. 4(d)). Pig femur relative FGF23 expression was increased $(P \leq 0.05)$ approximately 14 -fold in pigs produced by $+\mathrm{D}$ and $++\mathrm{D}$ sows compared with those produced by $-\mathrm{D}$ sows. Both femur and vertebra tissue relative FGF23 mRNA expressions were highly variable. Reasons for the variability of relative expression are not apparent. In a previous experiment, we reported even larger magnitudes of differences in metatarsal tissue FGF23 expression $^{(3)}$. The different bone measured in the current experiment offers one potential factor in the discrepancy between the two experiments.

\section{Discussion}

The initial impetus for the hypovitaminosis D kyphotic pig model was provided by an accidental omission in 2008 of vitamin D from a custom-mixed vitamin premix used as the primary supplement for our research herd. One of the primary symptoms, kyphosis, provided a visual skeletal abnormality as a functional consequence to deletion of vitamin D from sow diets and diets fed to young pigs. Until our research, kyphosis was classified as an idiopathic disease known to occur sporadically in commercial swine herds with an approximate $20 \%$ prevalence in afflicted herds ${ }^{(30)}$, as well as in human orthopaedic medicine. Our experiments have confirmed a role of vitamin D in kyphosis, and to our knowledge this was the first reproducible link between kyphosis and vitamin $\mathrm{D}^{(1,2)}$. The ability to reproduce kyphosis under controlled experimental conditions has allowed the study of the early events leading to these types of lesions, rather than depending on the final lesions when it is too late to intervene and possibly prevent. The hypovitaminosis D kyphotic pig has also proven to be a valuable model for human kyphosis research, especially paediatric Scheuermann's kyphosis ${ }^{(25)}$. Further characterisations of multiple bone 
abnormalities associated with the hypovitaminosis D kyphotic pig model ${ }^{(2,3,25)}$ have led to potential links of kyphotic lesions with osteochondrosis. Osteochondrosis is a common bone lesion in swine that results in major economic and welfare concerns for commercial producers. These lesions are also similar to skeletal abnormalities that are common in poultry, dogs, horses and humans.

On the basis of previously referenced animal knockout models and cell culture data, it was expected that pigs produced under conditions known to develop kyphosis would have decreased femur and vertebra $M M P 9, M M P 13, V E G F$ and FGF23 mRNA expression. However, results reported herein did not completely support this hypothesis.

The mRNA expression of $M M P 9, M M P 13$ and $V E G F$ in the current experiment did not reveal the same pattern as that of the knockout mouse and cell culture models described previously. Different results from a diet-induced animal model compared with those from GM knockout animals or in vitro cell culture models may not be surprising, as the latter results are often not completely extrapolated to a whole animal model response. Therefore, the role of these proteins in pathological bone and joint diseases may be more reliably reflected in responses displayed by the hypovitaminosis D kyphotic pig model.

The MMP proteins and VEGF have been implicated in cartilage, bone and joint disorders where these factors are usually up-regulated. The up-regulated response is opposite of that reported for the knockout models and vitamin D cell culture models. In these spontaneous, clinical disorders, an imbalance in the synthesis and degradation of tissue occurs, which leads to overall tissue degradation $^{(31)}$.

Synovial samples from human rheumatoid arthritis patients presented with increased $M M P 13$ expression $^{(32)}$. Similarly, expression of $M M P 1, M M P 3$ and $M M P 9$ was increased in human osteoarthritic tissue samples ${ }^{(33)}$. In human bone tissue samples of giant cell tumours and other osteolytic lesions, $M M P 9$ and VEGF expression continued to increase into the advanced stages of the diseases ${ }^{(34)}$. Although VEGF is upregulated in tissue samples of osteoarthritis and rheumatoid arthritis, this up-regulation is apparently achieved through different pathogenic pathways ${ }^{(17)}$.

Expression and biological activity of MMP9 and MMP2 were up-regulated in the synovial fluid from horses with aseptic and septic joint diseases ${ }^{(35)}$. In addition, MMP activity in synovial fluid from horses with osteoarthritis was increased, but no increase was detected in horses with osteochondrosis ${ }^{(31)}$. However, Mirams et $a l^{(36)}$. reported an increase in gene expression of $M M P 13$ in equine osteochondrotic tissue samples.

Differential expression patterns and timing according to the disease and stage of progression are all limitations in understanding the role of MMP and VEGF in cartilage, bone and joint disorders. Another limitation of data received from the aforementioned and other studies is that these measurements were made in animals that displayed the final stages of lesions of these diseases and/or a mechanically induced bone deformity animal model. Limited information is provided on the aetiology and progression of the disease and how expression levels of MMP and VEGF are altered during the initial stages of the lesions.
Although the mRNA expression of MMP9, MMP13 and VEGF in the hypovitaminosis D kyphotic pig model did not follow all of the patterns observed in the different animal and human disease models or the knockout models, responses to dietary D were detected. Most notable were the responses to maternal dietary D at the end of the 4-week nursery phase. In the current experiment, changes in the mRNA expression of these factors were detected before manifestation of the final kyphotic lesion, which is visibly detected only after 8-9 weeks of age in the kyphotic pig model. Therefore, further characterisation of these factors and other members of the MMP family potentially provide biomarkers to predict the risk of unfavourable offspring bone consequences from maternal dietary D deficiency during gestation and lactation.

Although no differences were detected in femur or vertebra FGF23 expression in most ages of pigs, the potential for a role of FGF23 in this model cannot be completely eliminated. Multiple factors must be considered and potentially altered in future experiments to determine whether FGF23 has a role in the initiation of bone abnormalities. The synthesis of FGF23 is dependent on the arrangement of the osteocyte lacunar canciular system, which is more organised in bone that is not remodelling, unlike the bones analysed in the present experiment. Additionally, FGF23 synthesis increases in the more organised areas which occur in regions towards the diaphysis of a growing bone ${ }^{(37)}$, as compared with the epiphysis which is where samples were collected from in the present experiment. The samples used for the present study were localised to the growth plate region of the bones; therefore it would have included younger, mostly trabecular, bone rather than cortical bone.

The discrepancy between the current and previously reported ${ }^{(3)}$ FGF23 results could potentially be explained by the difference in bones used (metatarsal $v$. femur and vertebra). At this age the metatarsal probably has less active remodelling compared with the femur and vertebra bones, and therefore the collected samples may have included increased cortical bone and osteocytes. Another potential source for the difference in relative FGF23 expression between the two experiments may be attributed to the change in $\mathrm{Ca}$ levels in the current experiment. The effects of D and P on FGF23 only occur in normal or hypercalcaemic conditions ${ }^{(23,24)}$. The evidence for differences in femur FGF23 expression in pigs at weaning and no differences at other ages in the current experiment is of interest, but remains to be completely explained.

The key regulators and molecular actions of FGF23 are not completely understood owing to the complex interaction of factors involved $^{(24,38,39)}$. Therefore, further work is warranted, especially in whole animal models, to more completely understand the potential role of FGF23 in bone lesion initiation and progression of bone abnormalities associated with an uncoupling of endochondral ossification in the hypovitaminosis D kyphotic pig model.

\section{Conclusions}

On the basis of results from the experiment reported herein, mRNA expression of $M M P 9, M M P 13$ and $V E G F$ offers potential markers for the initial developmental stages of bone lesions in the hypovitaminosis D kyphotic pig model. Although differences were not detected in the mRNA expression of FGF23 at 
all time points, the physiological interrelationship of this peptide with vitamin $\mathrm{D}, \mathrm{Ca}$ and $\mathrm{P}$ homoeostasis warrants continued assessment as a critical link to the early stages of bone responses to nutrient inputs. The model has provided a means to study pivotal cellular signals in the initiation and development of kyphosis and related bone abnormalities in a biologically relevant physiological system without the use of gene editing or surgical manipulation.

\section{Acknowledgements}

The authors acknowledge the University of Wisconsin Swine Research and Teaching Center staff for their meticulous animal care.

Funds to support this project were provided by the University of Wisconsin Hatch fund (PRJ42HD) and an unrestricted research fund (233-Q893) to support swine nutrition research. DSM Nutritional Products North America ( 45 Waterview Blvd., Parsippany, NJ 07054) donated the supplemental vitamin $D_{3}$ used in diet supplements, but had no role in the experimental design, analysis or writing of the manuscript.

L. A. A. and T. D. C. designed research, conducted research and wrote the paper; L. A. A., T. D. C. and L. L. H. analysed data; and L. A. A. had primary responsibility for final content. All authors read and approved the final manuscript.

The authors declare that there are no conflicts of interest.

\section{References}

1. Rortvedt LA \& Crenshaw TD (2012) Expression of kyphosis in young pigs is induced by a reduction of supplemental vitamin $\mathrm{D}$ in maternal diets and vitamin $\mathrm{D}, \mathrm{Ca}$, and $\mathrm{P}$ concentrations in nursery diets. J Anim Sci 90, 4905-4915.

2. Amundson LA, Hernandez LH \& Crenshaw TD (2017) Serum and tissue $25-\mathrm{OH}-\mathrm{D}_{3}$ concentrations do not predict bone abnormalities and molecular markers of vitamin D metabolism in the hypovitaminosis D kyphotic pig model. Br J Nutr 118, $30-40$.

3. Amundson LA, Hernandez LL, Laporta J, et al. (2016) Maternal dietary vitamin D carryover alters offspring growth, skeletal mineralization, and tissue mRNA expression of genes related to vitamin D, calcium, and phosphorus homeostasis in swine. Br J Nutr 116, 771-787.

4. Ortega N, Behonick DJ \& Werb Z (2004) Matrix remodeling during endochonral ossification. Trends Cell Biol 14, 86-93.

5. Stickens D, Behonick DJ, Ortega N, et al. (2004) Altered endochondral bone development in matrix metalloproteinase 13-deficient mice. Development 131, 5883-5895.

6. Sternlicht MD \& Werb Z (2001) How matrix metalloproteinases regulate cell behavior. Annu Rev Cell Dev Biol 17, 463-516.

7. Nagase H, Visse R \& Murphy G (2006) Structure and function of matrix metalloproteinases and TIMPs. Cardiovasc Res 69 , $562-573$

8. Blavier L \& Delaisse JM (1995) Matrix metalloproteinases are obligatory for the migration of preostoclasts to the developing marrow cavity of primitive long bones. J Cell Sci 108, 3649-3659.

9. Malemud CJ (2006) Matrix metalloproteinases: role in skeletal development and growth plate disorders. Front Biosci 11, 1702-1715.
10. Hasky-Negev M, Simsa S, Tong A, et al. (2008) Expression of matrix metalloproteinases during vascularization and ossification of normal and impaired avian growth plate. J Anim Sci 86, 1306-1315.

11. Krane SM \& Inada M (2008) Matrix metalloproteinases and bone. Bone 43, 7-18.

12. Vu TH, Shipley JM, Bergers G, et al. (1998) MMP-9/Gelatinase B is a key regulator of growth plate angiogenesis and apoptosis of hypertrophic chondrocytes. Cell 93, 411-422.

13. Inada $\mathrm{M}$, Wang $\mathrm{Y}$, Byrne $\mathrm{MH}$, et al. (2004) Critical roles for collagenase-3 (Mmp13) in development of growth plate cartilage and in endochondral ossification. Proc Natl Acad Sci US A 101, 17192-17197.

14. Engsig MT, Chen QJ, Vu TH, et al. (2000) Matrix metalloproteinase 9 and vascular endothelial growth factor are essential for osteoclast recruitment into developing long bones. J Cell Biol 151, 879-889.

15. Johansson N, Saarialho-Kere U, Airola K, et al. (1997) Collagenase-3 (MMP-13) is expressed by hypertrophic chondrocytes, periosteal cells, and osteoblasts during human fetal bone development. Dev Dyn 208, 387-397.

16. Carlevaro MF, Cermelli S, Cancedda R, et al. (2000) Vascular endothelial growth factor (VEGF) in cartilage neovascularization and chondrocyte differentiation: autoparacrine role during endochondral bone formation. $J$ Cell Sci 113, 56-69.

17. Murata M, Yudoh K \& Masuko K (2008) The potential role of vascular endothelial growth factor (VEGF) in cartilage - How the angiogenic factor could be involved in the pathogenesis of osteoarthritis? Osteoarthr Cartil 16, 279-286.

18. Ferrara N, Gerber HP \& LeCouter J (2003) The biology of VEGF and its receptors. Nat Med 9, 669-676.

19. Lin R, Amizuka N, Sasaki T, et al. (2002) 1 1 ,25-dihydroxyvitamin $\mathrm{D}_{3}$ promotes vascularization of the chondro-osseous junction by stimulating expression of vascular endothelial growth factor and matrix metalloproteinase 9. J Bone Min Res 17, 1604-1612.

20. Uchida M, Shima M, Chikazu D, et al. (2001) Transcriptional induction of matrix metalloproteinase-13 (Collagenase-3) by 1 $\alpha, 25$-dihydroxyvitamin $\mathrm{D}_{3}$ in mouse osteoblastic MC3T3E1 cells. J Bone Min Res 16, 221-230.

21. Sitara D, Razzaque MS, St-Arnaud R, et al. (2006) Genetic ablation of vitamin $\mathrm{D}$ activation pathway reverses biochemical and skeletal anomalies in Fgf-23-null animals. Am J Pathol 169, 2161-2170.

22. Lanske B, Densmore MJ \& Erben RG (2014) Vitamin D endocrine system and osteocytes. BoneKey Rep $\mathbf{3}$.

23. Rodriguez-Ortiz ME, Lopen I, Munoz-Castaneda JR, et al. (2012) Calcium deficiency reduced circulating levels of FGF23. J Am Soc Nephrol 23, 1190-1197.

24. David V, Dai B, Martin A, et al. (2013) Calcium regulates FGF-23 expression in bone. Endocrinol 154, 4469-4482.

25. Halanski MA, Hildahl B, Amundson LA, et al. (2018) Maternal diets deficient in vitamin D increase the risk of kyphosis in offspring. J Bone Joint Surg 100, 406-415.

26. National Research Council (2012) Nutrient Requirements of Swine, 11th ed. Washington, DC: The National Academies Press.

27. Schmittgen TD \& Livak KJ (2008) Analyzing real-time PCR data by the comparative CT method. Nat Protoc 3, 1101-1108.

28. Hittmeier LJ, Grapes L, Lensing RL, et al. (2006) Genetic background influences metabolic response to dietary phosphorus restriction. J Nutr Biochem 17, 385-395.

29. Hoenig JM \& Heisey DM (2001) The abuse of power: The pervasive fallacy of power calculations for data analysis. $\mathrm{Am}$ Stat 55, 19-24. 
30. Straw BR \& May G (2009) Anatomical abnormalities in a group of finishing pigs: prevalence and pig performance. J Swine Heath Prod 17, 28-31.

31. Brama PAJ, TeKoppele JM, Beekman B, et al. (1998) Matrix metalloproteinase activity in equine synovial fluid: influence of age, osteoarthritis, and osteochondrosis. Ann Rheum Dis 57, 697-699.

32. Stahle-Backdahl M, Sandstedt B, Bruce K, et al. (1997) Collagenase-3 (MMP-13) is expressed during human fetal ossification and re-expressed in postnatal bone remodeling and in rheumatoid arthritis. Lab Invest 76, 717-728.

33. Freemont AJ, Hampson V, Tilman R, et al. (1997) Gene expression of matrix metalloproteinases 1,3 , and 9 by chondrocytes in osteoarthritic human knee articular cartilage is zone and grade specific. Ann Rheum Dis 56, 542-549.

34. Kumta SM, Huang L, Cheng YY, et al. (2003) Expression of VEGF and MMP-9 in giant cell tumor of bone and other osteolytic lesions. Life Sci 73, 1427-1436.
35. Clegg PD, Coughlan AR, Riggs CM, et al. (1997) Matrix metalloproteinases 2 and 9 in equine synovial fluids. Equine Vet J 29, 343-348.

36. Mirams M, Tatarczuch L, Ahmed YA, et al. (2009) Altered gene expression in early osteochondrosis lesions. J Orthop Res 27, 452-457.

37. Ubaidus S, Li M, Sultana S, et al. (2009) FGF23 is mainly synthesized by osteocytes in the regularly distributed osteocytic lacunar canalicular system established after physiological bone remodeling. J Electron Microsc 58, 381-392.

38. Sitara D, Kim S, Razzaque MS, et al. (2008) Genetic evidence of serum phosphate-independent functions of FGF-23 on bone. PLoS Genet 4, e1000154.

39. Wang H, Yoshiko Y, Yamamoto R, et al. (2008) Overexpression of fibroblast growth factor 23 suppresses osteoblast differentiation and matrix mineralization in vitro. $J$ Bone Min Res 23, 939-948. 